\title{
Renascer das próprias cinzas: a formação e a atual problemática do sujeito
}

\author{
Rising from the ashes: the formation and present problem of the subject
}

Angelo Vitório Cenci*

\section{Resumo}

O artigo parte da premissa de que a problemática do sujeito é intrínseca à da formação humana, de modo a ter de ser atualizada toda vez que esta última for recolocada. Por conseguinte, uma concepção atualizada de formação e de sujeito tem de levar em conta as críticas ao modelo metafísico do sujeito moderno, mas sem abandonar a própria ideia de sujeito. No percurso argumentativo desenvolvido, retomam-se as críticas ao "sujeito moderno" enquanto metafísica da subjetividade, para, com base em perspectivas teóricas contemporâneas, delinear aspectos do que se entende ser uma concepção descentrada, pós-metafísica, intersubjetivista e situacional de sujeito. Defende-se que uma ideia de formação "renascida de suas próprias cinzas" e impulsionada por problemas educacionais da atualidade demanda a compreensão do sujeito como um si mesmo processual.

Palavras-chave: Formação. Si mesmo. Sujeito.

\section{Abstract}

The article starts from the premise that the problem of the subject is intrinsic human formation, so that it must be updated every time the latter is readdressed. Thus, an updated conception of formation and of subject must take into account the criticism to the metaphysical model of the modern subject, but without neglecting the very notion of subject. Arguments are drawn considering the criticism towards the "modern subject" as metaphysics of subjectivity to, based on contemporary theoretical perspectives, outline aspects of what is understood as a decentred, post-metaphysical, intersubjective and situational conception of subject. The argument is that the idea of formation "rising from its own ashes" and boosted by current educational problems requires understanding the subject as an ongoing self.

Keywords: Formation. Self. Subject.

Recebido em: 15/03/2017 - Aprovado em: 13/7/2017

http://dx.doi.org/10.5335/rep.v24i3.7760

Doutor em Filosofia pela Universidade Estadual de Campinas (2006) e com pós-doutorado realizado na mesma instituição (2012). Professor da Universidade de Passo Fundo e professor visitante da Universidad Nacional del Centro de la Província de Buenos Aires. E-mail: angelo@upf.br 


\section{Introdução}

[...] se o 'humano que a cada vez a mim se apresenta' é a figura do que tenho por mais familiar, ele é também a imagem do que desconheço mais inteiramente - tanto no outro quanto, diga-se de passagem, em mim mesmo (DO VALLE, 2014, p. 498).

Na mitologia grega, a fênix era apresentada como um pássaro longevo, dotado de força capaz de transportar cargas muito pesadas, e, a cada vez que morria, entrava em autocombustão e, depois, renascia de suas próprias cinzas. A célebre ave mitológica simboliza com perfeição a capacidade de renascimento de uma ideia que marcou desde a gênese os processos educativos no ocidente. Trata-se da ideia de formação que, da paideia grega, passando pela humanitas latina e pela Bildung moderna, chegando ao contexto atual, continua, mesmo quando relegada às próprias cinzas, a desafiar o pensamento educacional. Parodiando Kant (1972), poder-se-ia afirmar que, em razão de sua importância, mesmo que ninguém a levasse em conta, ainda assim ficaria brilhando como uma joia. No atual contexto educacional e seus reducionismos de várias ordens, defendê-la constitui-se em uma tarefa quase hercúlea, dados os enormes desafios a ela colocados. À primeira vista, o Zeitgeist e a herança metafísica que a impregnou sugeririam muito mais uma despedida do que sua defesa ou atualização. Obviamente, não se trata de postular tout court uma retomada de modelos de formação que perderam vigência histórica, embora não força normativa. Se, por um lado, tais modelos somente são inteligíveis na relação com o contexto no qual se constituíram, por outro, nunca terminaram de dizer o que tinham para dizer, a exemplo do que ocorre com os livros clássicos (CALVINO, 2007).

A primeira exigência presente no que se refere a um conceito atualizado de formação é, pois, a de estabelecer um diálogo crítico-renovador com a tradição e, ao mesmo tempo, a de não fazê-lo de modo anacrônico, mas articulado estreitamente a problemas emanados da realidade educacional. Como na mitologia, a metáfora das cinzas, das quais a ideia de formação tem a cada vez de renascer, pode ser interpretada como sinal tanto de sua superação pelo tempo, enquanto experiência histórica, quanto da renovação da força conceitual ainda presente no interior da longa tradição que a marca. Ambas, experiência histórica e tradição de pensamento, somadas aos grandes desafios educacionais da atualidade, constituem-se justamente no húmus que possibilita seu renascimento e fortalecimento hodiernamente. Se ainda faz sentido nos ocuparmos com ela é porque, tal como a fênix, essa força é potente o suficiente para ser revolvida e assim alimentar a chama dos processos educativos, dela renascer e, em última instância, orientar a própria constituição do humano. 
Com efeito, uma ideia de formação é indissociável de uma concepção do humano, como ensinaram pela primeira vez os gregos. É por essa razão que o clássico Paideia, de Werner Jeager (1994), leva como subtítulo a expressão "a formação do homem grego". Com os gregos, sob um prisma metafísico-essencialista, ocorre, pois, a descoberta dessa ideia, não como eu subjetivo, mas como "[...] consciência gradual das leis gerais que determinam a essência humana" (JEAGER, 1994, p. 14). Se a problemática do sujeito é intrínseca à da formação humana, ela tem, pois, de ser atualizada toda vez que essa última for recolocada. Por conseguinte, um conceito atualizado de formação passa pela necessidade de repensar o conceito de sujeito, sobretudo o modo como esse foi colocado na base das concepções filosófico-pedagógicas de formação, tanto em seu sentido clássico-essencialista ${ }^{1}$ quanto no modelo metafísico da subjetividade moderna.

Orientados por esse norte, a questão que nos serve de guia é: que concepção de sujeito deveria orientar uma ideia atualizada de formação? Para ser plausível - e essa é nossa hipótese -, uma tal concepção deveria levar adiante um diagnóstico de época do sujeito, uma retomada das "críticas ao sujeito moderno" e o delineamento de uma concepção descentrada, pós-metafísica, intersubjetivista e situacional de sujeito. Para tal, há que, diante dos limites expressos pela própria crítica do "sujeito moderno", destinada ao caráter autossuficiente e metafísico deste, repensá-lo criticamente e atualizá-lo. Nesse sentido, em vez de assumir uma problemática crítica in totum ao "sujeito moderno", haveria que se incorporar a crítica a certas pretensões desmesuradas que lhe foram conferidas e ressituá-lo com ela, mas para além dela. Para tal, iniciaremos retomando as críticas ao "sujeito moderno", sobretudo à metafísica da subjetividade (1). Na sequência, com base em perspectivas contemporâneas, delineamos aspectos do que entendemos ser uma concepção descentrada (2), pós-metafísica, intersubjetivista e situacional de sujeito, na forma de um si mesmo processual (3).

Trata-se, a nosso ver, de um esforço indispensável para o delineamento de uma concepção de formação que hoje tem de renascer de suas próprias cinzas e das cinzas de um modelo de educação permeado por reducionismos de várias ordens. Quanto à tarefa de esboçar um diagnóstico do sujeito contemporâneo, reservaremos a ela um futuro ensaio específico, sobretudo para abordar as formas de reducionismo e de negação deste aos moldes de determinadas patologias sociais. Não temos condições de desenvolver essa tarefa neste texto, mas um bom diagnóstico filosófico e sociológico do sujeito no tempo presente exigiria identificar e articular elementos dessa negação. ${ }^{2}$ 


\section{As críticas ao "sujeito moderno"}

Para a tradição iluminista e seus herdeiros do século XX, como Adorno, Piaget e Freire, a educação é entendida como um processo que possibilita aos indivíduos o desenvolvimento de seu potencial racional para tornarem-se sujeitos autônomos. Esse postulado entrelaçado à Bildung fora claramente colocado por Kant (1985) ao enunciar como lema do esclarecimento (Aufklarung) a coragem de fazer uso do próprio entendimento, o "Sapere aude!", e ao defender que a propensão humana para pensar e agir livremente seria possibilitada pela educação. De algum modo, pode ser encontrado também na filosofia da intersubjetividade, presente na teoria do reconhecimento do jovem Hegel (1976).

Todavia, a modernidade é marcada também pela metafísica da subjetividade. Como identificara Nietzsche, em Descartes e seu cogito e em Kant e seu eu transcendental, essa aparece por meio da redução do conceito de alma ao sujeito do conhecimento e suas funções lógicas, de modo a manter, mesmo com tal redução, pressupostos teológicos na esfera da teoria do conhecimento. Descartes é o precursor de tal metafísica no pensamento moderno, e ela se sustenta em uma tese dualista que compreende o homem como constituído por duas substâncias, a saber, a alma, ou a coisa pensante (res cogitans), e o corpo, ou a coisa extensa (res extensa). De acordo com essa tese, corpo e alma possuiriam atributos metafisicamente distintos. O pensamento seria tomado na forma da substância pensante, e o corpo, na forma de extensão, comprimento, largura e profundidade, comporia a substância física. É na sexta das Meditações que possivelmente se encontra a passagem mais representativa do dualismo, em que a alma aparece somente como uma substância pensante e o corpo, só como uma substância extensa:

[...] e embora eu talvez [...] possua um corpo que está ligado a mim muito estreitamente, tenho, por um lado, uma ideia clara e distinta de mim próprio, enquanto sou apenas uma coisa pensante, não extensa, e, por outro lado, uma ideia distinta do corpo enquanto ele é apenas uma coisa extensa, não pensante. Pelo que é certo que sou realmente distinto do meu corpo e que posso existir sem ele (DESCARTES, 1988, p. 207).

No Discurso do método, Descartes apresenta um fundamento inabalável para a filosofia e, por conseguinte, para todo o conhecimento e faz isso mostrando que, para duvidar de tudo, é preciso reconhecer a existência da dúvida, ou seja, do próprio pensamento. A verdade indubitável do cogito, o "penso, logo existo", demonstra que a alma é uma substância distinta do corpo cuja natureza é o pensamento, algo não dependente de qualquer coisa material (Cf. DESCARTES, 1991, p. 104).

O filósofo inglês Ryle (2005) critica a posição de Descartes, que concebe a mente como distinta do corpo e não aceita a teoria de que os estados mentais são distin- 
tos dos estados físicos. Ao cindir o homem em res cogitans e res extensa, Descartes distingue o mental do material, mas, no juízo de Ryle, sua teoria cairia num erro categorial ao relacionar corpo e alma como se pertencessem à mesma categoria lógica. $\mathrm{O}$ erro consiste em separar os processos mentais dos processos físicos. Ryle utiliza a expressão "o mito do fantasma da máquina" para refutar o dualismo cartesiano, considerando absurda a posição de Descartes em defender que a mente e o corpo operam separadamente. Para Ryle, conceber a mente funcionando como algo imaterial e de modo independente em relação ao corpo - habitando-o e governando-o - é concebê-la como se ela e o corpo vivessem autonomamente do mesmo modo como um fantasma viveria dentro de uma máquina. Na alegoria de Ryle, o fantasma seria a mente e a máquina, o corpo humano.

Com efeito, no século XX, sobretudo na segunda metade, os termos em que o potencial de autonomia do sujeito moderno e seu ideário pedagógico-formativo foram sustentados são colocados em questão por importantes correntes teóricas. A elas se filiam tradições como a psicanálise, as correntes da filosofia da linguagem, a teoria social crítica, uma leitura pós-estruturalista da filosofia francesa contemporânea, bem como toda a corrente da filosofia contemporânea que colocou o humanismo sob suspeita. ${ }^{3}$ Em que pese suas diferenças, as críticas ao "sujeito moderno" traduzem um esforço comum em dar conta de um sintoma, a saber, o de que um modelo autocentrado, solipsista e metafísico de sujeito não é mais satisfatório para pensar o humano nem os processos educativos.

A primeira das orientações (a), ancorada em Freud e Nietzsche, levou adiante sua crítica ao sujeito na forma de uma crítica psicológica. Essa posição caracteriza-se por colocar em dúvida a existência de uma transparência completa nas ações humanas, uma vez que existem forças e motivos da ação individual que independem da consciência. Essa orientação questiona a autonomia enquanto possibilidade humana de controle completo do próprio agir. Como pontua a esse respeito Wellmer (1993), o sujeito descentrado da psicanálise constitui-se muito mais como uma encruzilhada de forças psíquicas e sociais do que como dono dessas forças. Freud afirmou, paradigmaticamente, que "[...] o ego tropeça com limitações de seu poder dentro de sua própria casa" (1981, p. 2435). Sob a ótica de Nietzsche, o sujeito moderno expressaria uma espécie de redução do conceito de alma ao âmbito da teoria do conhecimento, visando afastá-lo, sem êxito, da conotação cristã assumida por tal conceito. Afirma o filósofo: “[...] antigamente se acreditava na 'alma', assim como na gramática e no sujeito gramatical: dizia-se que 'eu' é condição, 'penso' é predicado e condicionado - pensar é uma atividade, para a qual um sujeito tem que ser pensado como causa" (NIETZSCHE, 2005, p. 53). E prossegue: "Tentou-se, então, com tenacidade e astúcia dignas de admiração, enxergar uma saída 
nessa teia - se não seria verdadeiro talvez o contrário: 'penso', condição; 'eu', condicionado; 'eu' sendo uma síntese, feita pelo próprio pensar" (2005, p. 53, grifo do autor). Para Nietzsche, a ideia de sujeito enquanto unidade e causa do pensamento é ancorada na crença metafísico-religiosa na alma, esta tomada como algo eterno e substancial. A seu ver, é dessa noção de alma que resulta a ideia de sujeito como unidade e identidade, todavia, não haveria mais como se sustentar um eu fixo que se constituiria como núcleo da unidade subjetiva.

A filosofia da linguagem ordinária (b), com base no Wittgenstein tardio (2014) e em Saussure (1995), operou uma crítica que questiona a existência de uma constituição individual de sentido, colocando em xeque a imagem de um sujeito que, com suas vivências e intenções, seria a fonte das significações linguísticas. Ao dissolver a compreensão das significações como algo ideal ou dado na realidade, dissolve-se também a ideia de um sujeito tomado como autor e juiz inapelável de suas próprias intenções de sentido. A crítica filosófico-linguística do sujeito aponta para algo prévio a toda intencionalidade ou subjetividade, a saber: para sistemas linguísticos de significações e formas de vida. ${ }^{4} \mathrm{O}$ pressuposto dessa crítica reside em que o discurso individual depende sempre de um sistema de significados linguísticos previamente dados.

A crítica da razão instrumental ao sujeito moderno e à sua lógica da identidade (c) apresenta-se como uma radicalização da crítica psicológica (Cf. WELLMER, 1993). Ela aparece em Nietzsche, é radicalizada em Adorno e Horkheimer, faz-se presente em Foucault e na abordagem norte-americana, que interpreta parte da filosofia francesa contemporânea como pós-estruturalista. Na perspectiva de Adorno e Horkheimer (1985), a opressão dirigida à natureza humana interna em busca da felicidade constitui-se no preço a ser pago pela formação do eu enquanto um si mesmo unitário. A razão instrumental - pautada na eficácia da escolha dos meios para alcançar os fins desejados - teria encontrado sua expressão mais acabada na ciência moderna da natureza (Adorno e Horkheimer) e na ordem das ciências humanas (Foucault). Na ótica daqueles, o sujeito humano é desinflado, convertendo-se em um mero nó de engate entre as reações e as funções convencionais dele esperadas como algo objetivo. O eu se constituiria, na medida em que se sublimaria em um sujeito transcendental ou lógico, no "[...] ponto de referência da razão, a instância legisladora da ação" (ADORNO; HORKHEIMER, 1985, p. 41).

No Foucault lido em chave pós-estruturalista (d), o sujeito aparece como produto do discurso moderno. ${ }^{5}$ Essa perspectiva teórica compreende o sujeito moderno como monolítico, a saber, homogêneo, consciente, indivisível e centrado, guiado pela ordem e pelo controle. O sujeito não existiria a não ser na forma de um simples resultado de um processo de produção cultural e social. O pós-estruturalismo propõe 
um descentramento do sujeito, deslocando-o do prisma de uma suposta identidade coesa, monolítica e coerente para o de um lugar onde variados construtos socioculturais e formações discursivas agiriam entrecruzando-se e em conflito constante. Assim compreendido, o indivíduo não seria senhor de seu discurso nem de suas vontades, uma vez que é interpelado pela ideologia, e esta seria condição para a constituição tanto do sujeito quanto dos sentidos (Cf. PEIXOTO, 2008, p. 496).

Outra orientação (e) que coloca em questão a ideia de um sujeito metafísico e autárquico é a representada por pensadores como Foucault, Levinas e Heidegger, que ajudou a abalar a ideia metafísica de uma essência humana invariável que especificaria de antemão o significado do humano. Essa posição é bem traduzida pela famosa imagem foucaultiana (FOUCAULT, 1966) do homem como um rosto desenhado na areia à beira do mar e pelo argumento de Heidegger (1957) de que todo humanismo funda-se em uma metafísica, razão pela qual não conseguiria dar conta do modo de o ser humano existir no mundo. O humanismo é lido por essa orientação como uma compreensão que entende ser possível determinar a essência do ser humano. Sua superação constituir-se-ia, pois, em uma questão filosófica de primeira grandeza e, como o propõe Biesta (2013), trata-se também de um desafio fundamental colocado à educação na medida em que a questão da humanidade do ser humano for tomada como uma questão "radicalmente aberta", somente possível de ser respondida mediante a participação na educação e não antes desta. Essa posição não pode ser tomada, todavia, como não normativa. Ao contrário, deveria ser entendida na linha de Hannah Arendt (1989), ao afirmar que o ser humano possui uma condição humana e não uma natureza humana, na medida em que o que caracteriza a primeira é a pluralidade, o fato de sermos humanos (os mesmos) e, ao mesmo tempo, distintos um dos outros, isto é, singulares.

Essas cinco críticas à ideia de sujeito moderno devem, ao invés de sugerir uma despedida apressada em relação a esta e a suas bases teóricas, ser tomadas como importantes, mas parciais, e lidas como um impulso para recuperar seu potencial ainda válido e levar adiante sua atualização crítica. Tal impulso coloca os defensores do ideário pedagógico da autonomia do sujeito ou do sujeito da formação diante de uma encruzilhada: abandoná-lo, face aos limites expressos na ideia de um sujeito autossuficiente e metafísico, ou repensá-lo criticamente e atualizá-lo. Nesse sentido, em vez de uma problemática crítica in totum ao sujeito moderno, o que se impõe é a crítica a certas pretensões desmesuradas que lhe foram conferidas, sobretudo na forma de sujeito epistêmico e de sujeito autárquico. Por conseguinte, trata-se agora de ressituar o sujeito moderno como sujeito da formação de modo pós-metafísico, descentrado, intersubjetivo e situacional. 


\section{Uma concepção descentrada de sujeito}

As críticas ao "sujeito moderno" trouxeram, como saldo positivo, a necessidade de o sujeito humano ser concebido de modo descentrado, pós-metafísico, intersubjetivista e situacional. É somente no contexto contemporâneo que o conceito de sujeito reunirá condições de desprender-se de suas amarras metafísicas. Assim compreendida, a gênese do sujeito humano é fundamentalmente intersubjetiva, e sua identidade não se apresenta como um todo homogêneo em suas diferentes dimensões. Por conseguinte, nenhum sujeito humano é completamente transparente para si próprio. Três fatores descobertos no século XX contribuíram para essa compreensão descentrada: o inconsciente, a linguagem e a historicidade.

Com o inconsciente (a), aprendemos que nem sempre somos senhores de nossos atos e que esses, portanto, não nos são transparentes no grau que pensávamos, tampouco somos seres tão autônomos e racionais quanto imaginávamos ser. Como destacara Freud (1981), o poder do ego é limitado "dentro de sua própria casa", uma vez que muitas ações humanas são determinadas por desejos e motivações que ele próprio desconhece. Posteriormente, Lacan (2002) vai defender que o inconsciente, antes de ser um fato psíquico, é um fato linguístico, por ser "estruturado, tramado, encadeado, tecido pela linguagem", passando do domínio do aparelho psíquico - da vida mental e da representação - para o da linguagem, que envolve o sujeito e o significante. A linguagem é entendida, assim, não apenas como um meio de comunicação humana ou de representação do mundo, mas como o campo em que se constitui a subjetividade.

A linguagem (b) é mediada simbolicamente e carrega consigo um estoque de significados que é prévio à nossa entrada no mundo e que não é controlável pelos agentes, embora sempre recorra a eles para levar adiante a interação humana. Os seres humanos são sujeitos capazes de fala e ação, e o contexto em que agem é sempre constituído por um horizonte comum de sentido. A ação só é possível se houver um pano de fundo comum, linguístico, o qual possibilita a coordenação das ações. Esse pano de fundo é o mundo da vida, composto por um estoque de significados legados aos indivíduos pelo contexto sociocultural por meio do processo de socialização-individualização. No contexto contemporâneo, como destaca Flickinger, ocorre uma "despotencialização do sujeito dominador" do mundo, "[...] antes considerado sujeito conhecedor e dono do processo construtivo de nosso conhecimento, o homem descobre-se a si mesmo como sendo sujeito à história e, sobretudo, à linguagem" (2010, p. 38). Essa sujeição à história e à linguagem é o que nos permite entrar no mundo: palavras e significados não podem ser completamente dominados, o que também é verdade no que se refere à história, que é contingente, pois todo sujeito é historicamente situado. Com efeito, a linguagem, da mesma forma que o inconscien- 
te, indica existir forças presentes na ação individual reveladoras do fato de que o sujeito jamais pode controlar ou compreender por completo seu próprio agir. A ideia clássica da subjetividade - vinculada normativamente à completa autodeterminação individual - é colocada em questão, e, por conseguinte, não seria mais possível compreender o sujeito como um ser totalmente transparente e senhor de si próprio.

Por fim, a consciência da historicidade humana (c) indica que somos nós, humanos, que fazemos história, mas que, todavia, os processos históricos não são programados nem controlados por quem quer que seja. Por serem históricas, as situações podem ser modificadas, mas isso depende de diferentes variáveis. Marx afirmara que "[...] os homens fazem a sua própria história, mas não a fazem como querem; não a fazem sob circunstâncias de sua escolha e sim sob aquelas com que se defrontam diretamente, legadas e transmitidas pelo passado" (1977, p. 17). Os homens nunca detêm o total controle sobre as circunstâncias e sobre a história. Em sentido próximo ao de Marx, mas ancorada no pensamento grego, Hannah Arendt destaca que o revelar-se dos homens aos semelhantes nos processos histórico-sociais, mediante a ação e o discurso, é marcado por um teor reflexivo. Tal processo de revelação se volta sobre o próprio sujeito, uma vez que o ator desconhece e não controla sua própria identidade antes de expor-se aos outros mediante a ação e o discurso: "[...] o agente se revela sem que se conheça a si mesmo ou saiba de antemão ‘quem' revela" (ARENDT, 1989, p. 205). Essa revelação implica risco na medida em que o agente não dispõe previamente do conteúdo a revelar e que expressa aos outros sua novidade irredutível.

O inconsciente, a linguagem e a história são, pois, três dimensões constitutivas do humano, que os humanos não controlam. Freud, no texto supracitado (Cf. 1981, p. 2434-2435), refere três "feridas narcísicas" impingidas ao homem, respectivamente, por Copérnico, Darwin e por ele próprio. Copérnico afirmou que a terra não é o centro do universo, de modo que o heliocentrismo destronou o geocentrismo e impingiu ao homem a "ferida cosmológica". A concepção da Terra como centro garantia a função do homem como ser predominante no universo, de modo a poder sentir-se como dono e senhor do mundo. Darwin revelou que nossa origem não é tão nobre quanto imaginávamos e que não somos seres tão prediletos como nos fizeram crer. Nesse sentido, o homem abriu um abismo para com relação aos outros seres, negou-lhes racionalidade, atribuiu-se uma alma imortal e uma origem divina. Darwin expôs a "ferida biológica", colocando fim a essa exaltação do homem ao mostrar que ele não é distinto nem melhor do que o animal, mas tem com esse um parentesco próximo. O próprio Freud, por sua vez, impingiu ao homem a "ferida psicológica", e esta incidiu sobre o seu sentir-se soberano em sua própria alma. Essa alma, argumentou, não controla seus impulsos, não é algo simples, mas se 
constitui numa hierarquia de instâncias e em uma confusão de impulsos que tendem - de modo independente uns dos outros - a manifestarem-se na multiplicidade das pulsões e nas relações com o mundo exterior.

Ricoeur e Foucault, por sua vez, vão referir-se ao papel desempenhado por Marx, Freud e Nietzsche como o de três "mestres da suspeita" (expressão cunhada por Ricoeur). A consciência é colocada por eles sob suspeita, ao fazerem a crítica à ideia cartesiana de que aquela permitiria apreender o sentido do mundo e de si mesma de maneira evidente, clara e distinta. Para Ricoeur, a partir dos mestres da suspeita, "[...] procurar o sentido não significa mais soletrar a consciência do sentido, mas decifrar suas expressões" (1977, p. 37-38). Já para Foucault, "Marx, Nietzsche e Freud nos põem diante de uma nova possibilidade de interpretações [...]" (2000, p. 42). Do ponto de vista de Ricoeur, o cogito cartesiano - expresso na fórmula "penso, logo existo", que permitiria a autoapreensão imediata do sujeito é colocado sob suspeita pela descoberta do inconsciente em Freud, do ser social em Marx e da vontade de poder em Nietzsche. Freud provou que nem sempre somos senhores de nossos próprios atos e que o inconsciente coloca em questão o poder conferido ao sujeito pensante moderno. Marx, por meio do conceito de ideologia, mostrou que nossas ideias nem sempre são tão nossas quanto pensávamos ser. Nietzsche indicou que a crença na unidade do eu deixa de levar em conta que o cogito postulado de Descartes é o resultado de múltiplos processos, que sobre esses atuam diversas esferas infraconscientes e que estas se encontram em jogo ou em conflito instintual. Por conseguinte, a consciência seria apenas um fenômeno de superfície e, ao invés de una, seria múltipla.

\section{Uma concepção pós-metafísica, intersubjetivista e situacional de sujeito}

Incorporando o descentramento do sujeito e a consciência dos limites do conceito de sujeito da metafísica clássica e moderna, o pensamento contemporâneo opera não apenas uma mudança terminológica, de sujeito (subjectum) para si mesmo (Self), mas também de sentido, de modo a compreender este como processo ao invés de substância. Sob esse prisma, a identidade só pode ser constituída socialmente, e Mead dá um passo além tanto em relação à tradição do sujeito como substância (metafísica clássica) quanto no que refere ao sujeito como interioridade distinta e oposta ao mundo, autárquico, autocentrado e completamente transparente a si mesmo (metafísica moderna). Para Mead (1968), a consciência humana não é algo suprassensível, mas resultado de processos interativos levados adiante pelo indivíduo com outros organismos e com o ambiente em que está inserido. Por essa razão, o autor esclarece que não podemos identificar o si mesmo (Self) com a 
consciência na forma de uma "presença privada ou subjetiva dos caracteres dos objetos" (MEAD, 1968, p. 197). Além disso, o si mesmo (Self) não é uma estrutura inata, tampouco se identifica com a posse de um corpo físico enquanto organismo fisiológico. O si mesmo não está presente inicialmente no nascimento, mas “[...] é algo que tem desenvolvimento [...], que surge no processo da experiência e das atividades sociais, isto é, se desenvolve no indivíduo como o resultado de suas relações com esse processo como um todo e com os outros indivíduos que se encontram dentro desse processo" (MEAD, 1968, p. 167).

A consciência só alcança a consciência de si mediante a interação social, que é simbólica e mediada pela linguagem. Como indica Habermas (1990), na esteira de Mead, a autoconsciência não "habita o sujeito", mas é um fenômeno gerado comunicativamente, via relação simbolicamente mediada com os parceiros de interação, de fora para dentro. Há um "núcleo intersubjetivo" na autoconsciência, e sua posição excêntrica atesta a dependência da subjetividade em relação à linguagem. A linguagem é o meio de o sujeito constituir-se e de reconhecer-se no outro de modo não objetivador. O pensamento pedagógico contemporâneo, herdeiro da tradição moderna iluminista e da herança desta recolhida por autores como Mead, Habermas e Honneth, entende que não nascemos humanizados e que temos de nos tornar assim de modo singular, sendo condicionados por nossa finitude. Já não imaginamos ser possível conhecer a "natureza" do ser humano, uma vez que cada indivíduo não pode mais ser entendido como um exemplar de uma essência já especificada e conhecida de antemão (BIESTA, 2013). Cada indivíduo tem de ser tomado em sua singularidade como radicalmente aberto e constituído intersubjetivamente.

O Self é aberto e processual, constituindo-se em uma dialética permanente entre as dimensões do $I$ e do $M e$. Como refere Casagrande, isso é possível na medida em que "[...] o sujeito desenvolve essa capacidade ou estrutura interna que o diferencia, individualizando-se reflexivamente e, ao mesmo tempo, permanecendo membro de uma comunidade" (2014, p. 63). O acesso ao si mesmo (Self) somente é possível mediado por um mim $(M e)$, que é a consciência de si originada das demandas, dos papéis e das perspectivas generalizadas advindas do meio/comunidade. Isso significa que é somente por meio da linguagem e da interação que o sujeito constitui um Self enquanto consciência de si mesmo. Não há consciência de si sem a interação com o outro, o que significa que somente de modo aberto, pela via processual e intersubjetiva, é que o Self pode se estruturar. Para constituir-se, o Self experimenta-se como um objeto para si, e isso ocorre na atividade social. Esse experimentar-se a si mesmo somente é possível indiretamente, ou seja, "[...] desde os pontos de vista particulares dos outros membros individuais do mesmo grupo 
social ou desde o ponto de vista generalizado do grupo social, como um todo, ao qual pertence" (MEAD, 1968, p. 170).

Para Mead, é somente à medida que o indivíduo reúne condições de assumir a atitude do outro que ele se torna capaz de constituir-se como um si mesmo (Self), ou seja, descentrando-se. Em outros termos, o si mesmo só se estrutura como tal na medida em que conhecemos o outro em sua relação conosco. "Alguém se converte em uma pessoa [Self] na medida em que pode adotar a atitude de outro e agir em relação a si mesmo como agem os outros" (MEAD, 1968, p. 199). Além disso, se as atitudes ou ações do indivíduo presumem o adotar a atitude do outro (as reações da comunidade) $[\mathrm{Me}]$, o indivíduo $[I]$ no qual elas se organizam "[...] tem a oportunidade de dar-lhes uma expressão que, quiçá, nunca tiveram antes" (MEAD, 1968, p. 223). É por essa razão que Habermas vai resumir a posição de Mead por meio da súmula "individuação através da socialização". De acordo com Habermas, "A identidade de indivíduos socializados, forma-se simultaneamente no meio do entendimento linguístico com outros e no meio do entendimento intra-subjetivo-histórico-vital consigo mesmo. A individualidade forma-se em condições de reconhecimento intersubjetivo e de auto-entendimento mediado intersubjetivamente" (1990, p. 186-187). O sujeito vai incorporando os papéis e as pautas sociais mediante os quais os demais sujeitos respondem ao seu comportamento comunicativo.

$\mathrm{Na}$ esteira de Mead e Habermas, Axel Honneth (2003) mostra que a constituição da identidade subjetiva individual (o $E u$ ) pressupõe o reconhecimento recíproco (intersubjetivo) entre dois sujeitos. A tese é assim detalhada pelo autor: "[...] só quando dois indivíduos se veem confirmados em sua autonomia por seu respectivo defrontante, eles podem chegar de maneira complementária a uma compreensão de si mesmos como um Eu autonomamente agente e individuado" (HONNETH, 2003, p. 119-120, grifo do autor). Essa tese afirma que a identidade pessoal possui, fundamentalmente, uma "estrutura intersubjetiva" (HONNETH, 2003, p. 272). Da abordagem de Mead e da tradição que dele resulta, tem-se que a constituição do humano demanda como outro de seus aspectos centrais o da intersubjetividade. Somente somos o que somos em nossa identidade - sempre aberta - mediante a interação com os outros. Nossa identidade é constitutivamente intersubjetiva, o que indica a profunda vulnerabilidade de nossa condição. Nós somos muitos, no sentido de que parte da pessoa dos outros e, pois, da humanidade, assim como do ambiente que fazemos parte, está em nós. Não há formação do humano sem a constituição de um núcleo referencial (identidade) singular por parte do sujeito, e a constituição de tal núcleo passa pela mediação com o outro e com o meio.

Aos aspectos da vulnerabilidade e da intersubjetividade vincula-se toda uma dimensão situacional do próprio si mesmo. Estudos como os de Philip Zimbardo, na 
psicologia social, e Kwame Appiah, na ética, criticam a ideia essencialista de que o sujeito - identificado por seu caráter - seria uma espécie de fortaleza ou estrutura homogênea capaz de resistir a situações moral e socialmente adversas em todas os contextos. Zimbardo (2012) lembra que as circunstâncias (grupos, instituições, sistemas) possuem um grande poder sobre os indivíduos, de modo a fazer parte direta e permanentemente de sua constituição. Isso faz com que o núcleo referencial do sujeito, por melhor constituído que seja, possa ser vulnerável a circunstâncias não familiares. Sua autonomia não é absoluta, pois é mediada com o meio, e este, quando deteriorado, pode colocá-la em xeque. O que é colocado em questão, destaca, por sua vez, Appiah, é a ideia de que o caráter implica uma constância: “[...] grande parte do proceder das pessoas se explica melhor não pelos traços do caráter, mas por tendências humanas sistemáticas em responder a características das situações particulares que antes não foram consideradas em absoluto como decisivas" (2010, p. 56).

Essa perspectiva situacionista, mas não relativista, alerta para o fato de que costumamos subestimar o papel da situação, das instituições e dos sistemas e superestimar o das disposições internas. Não seriam sustentáveis, desse modo, nem a representação clássica de um sujeito fechado, pronto (caráter), nem a de um sujeito autárquico e invulnerável às circunstâncias que o permeiam. A compreensão contemporânea leva em conta o ser humano como ser situado na história, em contexto, finito, aberto, etc. Esses aspectos também são universais, mas não no sentido de algo fechado, como o era para a metafísica clássica. Os processos educativos não podem deixar de considerar essa dimensão sob o risco de ainda ficarem presos a uma concepção metafísica de sujeito e de formação humana.

\section{À guisa de conclusão}

A questão que nos guiou concerniu à que concepção de sujeito deveria orientar uma ideia atualizada de formação. Defendemos a hipótese de que, para ser plausível, tal concepção deveria retomar e incorporar criticamente as "críticas ao sujeito moderno" e delinear uma concepção descentrada, pós-metafísica, intersubjetivista e situacional de sujeito. Levamos adiante esse esforço retomando tais críticas e apresentando brevemente aspectos acerca do que caracterizaria uma concepção de sujeito na forma de um si mesmo aberto e processual. À luz de correntes do pensamento contemporâneo, defendemos que nosso si mesmo não é um eu homogêneo e linear, e as circunstâncias em que agimos mostram que ele é aberto e contraditório, pois sempre podemos explicitar novas facetas dele na relação com o meio. A identidade não se configura de modo homogêneo e muito menos na forma de uma interioridade oposta a um mundo exterior, mas se desenvolve na medida em que 
o sujeito é interpelado pelo ambiente e responde a ele, como mostrara Mead e em conformidade com o que atestam Zimbardo e Appiah. Nesse sentido, novas facetas da identidade, antes desconhecidas pelo próprio sujeito, manifestam-se nessa interpelação, uma vez que este é compreendido como poroso, não mais homogêneo, fechado e autossuficiente.

Nossa premissa foi a de que só é possível sustentar, ainda, uma ideia de formação se se delinear minimamente uma concepção de sujeito, que deve incorporar as críticas ao "sujeito moderno", como a do caráter metafísico deste, mas de modo relativizado, ou seja, sem abandonar seus alcances. Uma concepção descentrada de sujeito demanda a consciência de que não somos completamente transparentes a nós mesmos, o que coloca em questão o sentido do sujeito autárquico e sua onipotência em conceber o humano. Muda, desse modo, o sentido da autonomia, convertendo-se em autonomia descentrada. Tal concepção demanda também uma compreensão pós-metafísica, visto que não há mais uma essência a atualizar nem a dicotomia entre interioridade e exterioridade própria da metafísica da subjetividade moderna. $\mathrm{O}$ sujeito passa a ser entendido como um si mesmo processual, não mais como substância ou coisa inteligível. Um sujeito descentrado e pós-metafísico também não pode ser concebido de modo individualista ou em oposição ao outro, uma vez que esse outro não deve ser entendido como uma limitação de si, mas como uma condição de sua própria liberdade e subjetividade (HONNETH, 2015). Por fim, trata-se de uma identidade distante de ser homogênea, fechada e linear, já que se constitui de modo sempre aberto e em confronto com si mesma e em interdependência com os outros, as instituições e os sistemas sociais.

Esse modo de entender a constituição do humano implica importantes consequências ao papel do educador, uma vez que este tem de conduzir um processo que envolve seres singulares e que não pode ser controlado como se manejaria 0 controle de qualidade numa linha de produção em escala industrial. Hannah Arendt (1989) já argumentara que, enquanto os demais seres vivos são exemplares de uma espécie e se definem de acordo com as características essenciais gerais dessa espécie, os humanos são seres singulares. Por essa razão, ao invés de o sujeito ser tomado a partir de sua suposta "natureza", deveria ser compreendido a partir de sua "condição". E essa condição reside na "pluralidade" e no fato de que, apesar de sermos todos iguais enquanto humanos, somos radicalmente singulares. Em nossa leitura, essa é a condição de seres que agregam em si contradições e facetas desconhecidas a si próprios, sem uma essência ou uma interioridade oposta a um mundo exterior; de seres em que o outro é parte e condição do si mesmo; e, ainda, de seres que se constituem em situações permeadas e condicionadas relativamente por instituições e sistemas sociais. Essa concepção do si mesmo demanda uma ideia 
de formação consoante, o que faz lembrar a advertência de Adorno (1995) de que não podemos formar pessoas do mesmo modo como regamos plantas. É, pois, a nosso juízo, das cinzas da tradição e de uma concepção de sujeito brotada do viço do pensamento contemporâneo que a ideia de formação tem hoje de renascer.

\section{Notas}

1 O modelo clássico essencialista remonta a Platão e a Aristóteles. Esse último pensa a especificidade do homem com base na relação metafísica ato-potência e em termos de gênero e diferença específica, próprios de sua biologia fixista. Desse modo, em sua Política (I, 1), indica que o homem pertence ao gênero dos seres viventes, e sua diferença específica reside em ser político. Por essa razão, define-o como "ser vivente político", zoon politikon. Outra variante dessa concepção pode ser encontrada na teoria da reminiscência que aparece no diálogo Menon, de Platão (1991), e reside na ideia de que aprender é recordar. Desse modelo resultaria, posteriormente, uma epistemologia apriorista no sentido como o define Becker: "[...] essa epistemologia acredita que o ser humano nasce com o conhecimento já programado na sua herança genética" (2001, p. 20).

2 Nesse sentido, seria indispensável recorrer-se a estudiosos como Dardot e Laval (2016) (sujeito neoliberal), Ehrenberg (1998) (sujeito cerebral), Sennett (2006) (sujeito flexível), Illouz (2007) (sujeito emocionalmente dirigido), Honneth (2003) (sujeito-trabalhador empresário de si mesmo), etc. Implicaria ver também o quanto a ideia de um sujeito atomizado é devedora do modelo do homo clausus (ELIAS, 1994), que aparece claramente em muitas formulações do pensamento econômico liberal do século XVIII. Exemplo clássico dessa concepção pode ser encontrado na obra A fábula das abelhas, de 1723, do holandês Bernard Mandeville (2001), precursora da doutrina do laissez-faire. Nessa, vícios privados, como a ganância, a inveja, a vaidade e o orgulho, gerariam, de modo não intencional, benefícios públicos traduzidos na prosperidade da nação. O canadense Macpherson (1979) abordou essa mesma problemática em sua obra A teoria política do individualismo possessivo, de 1962, e sua tese é a de que a democracia liberal tem suas origens históricas e sociais no individualismo possessivo refletido no pensamento político inglês, cuja origem remontaria já ao século XVII (de Hobbes a Locke). A qualidade possessiva desse individualismo reside em "[...] sua concepção de indivíduo como sendo essencialmente o proprietário de sua pessoa e de suas próprias capacidades, nada devendo à sociedade por elas" (1979, p. 15). A forma atual dessa atomização do sujeito se aprofundou e se transmutou no "[...] desenvolvimento da lógica do mercado como lógica normativa generalizada" (DARDOT; LAVAL, 2016, p. 34).

3 Vale destacar o caráter difuso, um tanto precário e mesmo ambíguo da própria expressão "sujeito moderno". A rigor, não existe um "sujeito moderno" se entendido como um conceito que agregaria uma definição standard sob a qual se poderia unificar concepções tão ricas, complexas e distintas como as de Descartes, Rousseau, Kant, Stuart Mill e Hegel, entre outros grandes autores modernos. Geralmente, o uso da expressão "sujeito moderno" limita-se indistintamente ao modelo do cogito cartesiano e de sua metafísica da subjetividade e ao modelo do sujeito transcendental de Kant.

4 A esse respeito, vide Habermas (1990, parte II).

5 O pós-estruturalismo, tal como entendido aqui, concerne a uma leitura específica, de origem norte-americana, de autores franceses contemporâneos, como o primeiro Foucault, Derrida, Deleuze, Lyotard, Baudrillard e outros. Nessa linha de interpretação, inserem-se, entre outros, Peters (2000) e Silva (1994).

\section{Referências}

ADORNO, T. W. Educação e emancipação. 2. ed. Rio de Janeiro: Paz e Terra, 1995.

ADORNO, T.; HORKHEIMER, M. Dialética do esclarecimento. Rio de Janeiro: Jorge Zahar, 1985.

APPIAH, K. A. Experimentos de ética. Buenos Aires; Madrid: Katz, 2010.

ARENDT, H. A condição humana. Rio de janeiro: Forense Universitária, 1989. 
ARISTÓTELES. La politique. Paris: Vrin, 1962.

BECKER, F. Educação e construção do conhecimento. Porto Alegre: Artmed, 2001.

BIESTA, G. Para além da aprendizagem: educação democrática para um futuro humano. Belo Horizonte: Autêntica, 2013.

CALVINO, I. Por que ler os clássicos. São Paulo: Companhia das Letras, 2007.

CASAGRANDE, C. G. H. Mead \& a educação. Belo Horizonte: Autêntica, 2014.

DARDOT, P.; LAVAL, C. A nova razão do mundo: ensaio sobre a sociedade neoliberal. São Paulo: Boitempo, 2016.

DESCARTES, R. Discurs de la méthode. Paris: Gallimard, 1991. . Meditações sobre a filosofia primeira. Coimbra: Almedina, 1988.

DO VALLE, L. Para além do sujeito isolado modelos antropológicos para pensar a educação. Revista Brasileira de Educação, Rio de Janeiro, v. 19, n. 57, p. 495-512, abr./jun. 2014.

EHRENBERG, A. La fatigue d'être Soi: depresión et société. Paris: Odile Jacob, 1998.

ELIAS, N. A sociedade dos indivíduos. Rio de Janeiro: Jorge Zahar, 1994.

FLICKINGER, H.-G. A caminho de uma pedagogia hermenêutica. Campinas, SP: Autores Associados, 2010.

FOUCAULT, M. Les mots et les choses: une archéologie des sciences humaines. Paris: Gallimard, 1966.

Arqueologia das ciências e história dos sistemas de pensamento. Rio de Janeiro: Forense Universitária, 2000. (Ditos e Escritos II).

FREUD, S. Una dificultad del psicoanalisis. In: Madrid: Biblioteca Nuova, 1981. v. III. p. 2432-2436. Sigmund Freud - Obras completas.

HABERMAS, J. Pensamento pós-metafísico: estudos filosóficos. Rio de Janeiro: Tempo Brasileiro, 1990.

HEGEL, G. W. F. Système de la vie éthique (1802-1803). Paris: Payot, 1976.

HEIDEGGER, M. Lettre sur l’humanisme. Paris: Aubier, 1957.

HONNETH, A. Luta por reconhecimento. São Paulo: Editora 34, 2003.

. Le droit de la liberté. Esquisse d’une éthicité démocratique. Paris: Gallimard, 2015. ILLOUZ, E. Intimidades congeladas: las emociones en el capitalismo. Buenos Aires: Katz, 2007.

JEAGER, W. Paideia: a formação do homem grego. São Paulo: Martins Fontes, 1994.

KANT, I. Fondements de la métaphysique des moeurs. Paris: Vrin, 1972.

. Resposta à pergunta o que é o esclarecimento? In: Petrópolis, RJ: Vozes, 1985. p. 100-117. . Textos escolhidos. 2 . ed. 
LACAN, J. O seminário, livro 3: as psicoses. Rio de Janeiro: Jorge Zahar, 2002.

MANDEVILLE, B. La fabula de las abejas. México: Fondo de Cultura Económica, 2001.

MACPHERSON, C. B. A teoria política do individualismo possessivo. Rio de Janeiro: Paz e Terra, 1979.

MARX, K. O 18 brumário. In: . O 18 Brumário e Cartas a Kugelmann. 3. ed. São Paulo: Paz e Terra, 1977. p. 1-143.

MEAD, G. H. Espíritu, persona y sociedade. Buenos Aires: Paidós, 1968.

NIETZSCHE, F. Além do bem e do mal. São Paulo: Companhia de Bolso, 2005.

PEIXOTO, C. R. C. A linguagem, o sujeito e o currículo no pós-estruturalismo: reflexões para a prática de leitura em Língua Estrangeira. Revista Eutomia, Recife, a. I, n. 1, p. 489-508, 2008.

PETERS, M. Pós-estruturalismo e filosofia da diferença: uma introdução. Belo Horizonte: Autêntica, 2000.

PLATÓN. Menon. In: Obras completas. Madrid: Aguilar, 1991. p. 438-460.

RICOEUR, P. Da interpretação: ensaio sobre Freud. Rio de Janeiro: Imago, 1977.

RYLE, G. El concepto de lo mental. Barcelona: Paidós Ibérica, 2005.

SAUSSURE, F. Cours de linguistique générale. Paris: Payot, 1995.

SENNETT, R. A corrosão do caráter: consequências pessoais do trabalho no novo capitalismo. 11. ed. Rio de Janeiro; São Paulo: Record, 2006.

SILVA, T. T. (Org.). O sujeito da educação: estudos foucaultianos. Petrópolis: Vozes, 1994.

WELLMER, A. Sobre la dialéctica de modernidade y postmodernidad. Madrid: Visor, 1993.

WITTGENSTEIN, L. Recherches philosophiques. Paris: Gallimard, 2014.

ZIMBARDO, P. O efeito Lúcifer: como pessoas boas se tornam más. Rio de janeiro: Record, 2012. 